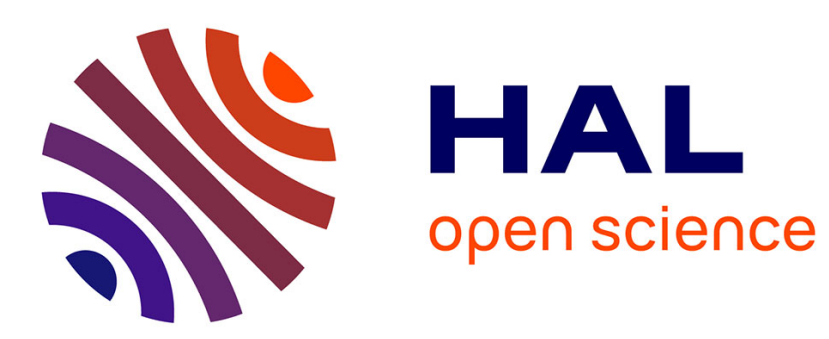

\title{
Rescheduling In The Urban Transportation Networks
}

Khoat Nguyen Duc, Bernard Descotes-Genon

\section{To cite this version:}

Khoat Nguyen Duc, Bernard Descotes-Genon. Rescheduling In The Urban Transportation Networks. 2006 International Conference on Service Systems and Management, 2006, Troyes, France. pp.15011506. hal-00149634

\section{HAL Id: hal-00149634 https://hal.science/hal-00149634}

Submitted on 28 May 2007

HAL is a multi-disciplinary open access archive for the deposit and dissemination of scientific research documents, whether they are published or not. The documents may come from teaching and research institutions in France or abroad, or from public or private research centers.
L'archive ouverte pluridisciplinaire HAL, est destinée au dépôt et à la diffusion de documents scientifiques de niveau recherche, publiés ou non, émanant des établissements d'enseignement et de recherche français ou étrangers, des laboratoires publics ou privés. 


\title{
Rescheduling In The Urban Transportation Networks
}

\author{
Nguyen-Duc Khoat, Descotes-Genon Bernard \\ Laboratoire d'Automatique de Grenoble - ENSIEG - INPG, BP 46 - 38402 Saint-Martin d'Hères \\ khoat.nguyen-duc@inpg.fr, bernard.descotes-genon@inpg.fr
}

\begin{abstract}
In this paper, we consider a real time regulation of traffic within a disturbed transportation networks. We aim to find a new schedule for transit system of buses after the detection of a disturbance at a given time. The main objective is to minimize waiting time of transferring and non transferring passengers at stations. This problem was already studied with evolutionary approach and multi-agents techniques in the case of unlimited buses capacities. In case of a limited bus capacity the problem becomes difficult to solve. In this paper, we will present an approach using genetic algorithms to solve this problem.
\end{abstract}

Keywords: Real time rescheduling, Genetic Algorithms, Urban transportation network.

\section{INTRODUCTION}

In public transport system, providing a reliable service is the main objective of operation managers. Timetables, minimum passengers' waiting times and short travel times are some instances of reliable services. The great difficulty related to traffic management of public transport system is associated with the respect of the planned arrival and departure times of the buses at different stations in the network. In fact, many disturbances can occur and affect the planned arrival and departure times and also affect the passengers' waiting times, the transit operations and the duration of different trips on the buses. So to reduce effects of disturbances, the initial schedules have to be adapted to real time conditions of the traffic. This adaptation is in fact call real time control strategies.

Real time control strategies are designed to enhance the system's ability to remedy specific problem as they occur [6].

These strategies could be divided into two categories:

\section{- Station control \\ - Deadheading and adding reserve bus.}

The first category, station control, includes delaying strategies (holding strategies) and stop-skipping strategies. These strategies are the most popular and frequently used by public transit operators to reduce passengers' waiting times.

Holding strategies are used to delay bus movement, when a bus is ahead of the schedule. Holding strategies could reduce the headway variance and the average waiting time of passengers, but also increase in-bus time of passengers and bus travel time.

Stop-skipping strategies aim to reduce travel time of the bus of interest. This would reduce the waiting time for passenger in-bus. However, this might increase the waiting time for passengers at skipped station, and those who are requested by the driver to alight at a given station to wait for the next bus in service.

The second category includes deadheading and adding reserve buses.
A deadheading bus strategies are the one having a bus that usually depart empty from a dispatching terminal point to a designate station, skipping stations between the dispatching terminal point and the designated station. This strategy could reduce both passengers' waiting time at the station beyond skipped ones, and the headway irregularity in the network.

Adding reserve buses strategies are useful when there are unexpected interruptions in the networks (traffic jam, accident, etc) Adding reserve buses to a service can reduce passengers' waiting time, and prevent headway irregularity in the network, but it might inflict additional costs on Transport Company.

Among the strategies surveyed above, holding strategies are the focus of this paper for rescheduling problem. In this paper, holding strategies use the mathematical programming models with holding time as decision variables and passengers' waiting time as the objective function to be minimized.

References [2],[6] formulated an aggregation of three criteria representing the total travel time, total waiting time, and total transfer time. This aggregation relies on weight parameters representing the relative importance of the criteria according to the disturbances and the regulator objectives. To solve this aggregation, an evolutionary approach was used.

In their solutions, the rescheduling problem dealt first with finding the new routes assigned to the different buses and then the schedules that satisfy different constraints. Reference [4] described a new hybrid evolutionary approach that aims to assist regulator of traffic in their decision to optimally the balance of the benefits to operator and passengers. In this study, the problem is again formulated and introduced the waiting time of passengers who were left behind at stations by bus, similar to that defined by [2], [6].

This paper also presents a mathematical model for the rescheduling problem, which is applicable to bus transit operations in the urban. The model presented in this paper could be viewed as an extension to that of [2], 
[4] and [6], as their application is limited to bus unlimited capacity.

The mathematical model presented in this paper contains some real conditions in the bus operation. This requires altering the objective function and the addition of constraint equation. The objective of this model is to minimize the waiting time of non-transferring and transferring passengers at any stations when disturbances happen in the network. The remainder of this paper is organized as follows. Section 2 describes the problem statement. Section 3 presents the mathematical model. A Genetic approach used to solve this model is presented in section 4. Section 5 shows an example and some results. Section 6 is for the conclusion.

\section{PROBLEM STATEMENT}

The problem considered herein investigates a strategy that could be applied to rescheduling an operation of $B$ buses on a specified line with $S$ stations.

It is assumed that at a given moment disturbances occur in the network and affects buses at the stations of a certain line. Consequently, theoretical schedules cannot be followed exactly, that compels trips to start late and causes passenger to wait longer. Therefore, to reduce effects of the disturbances, the theoretical schedules have to be adapted to real traffic conditions through rescheduling tasks. Consequently, it will reduce the waiting time of passengers by under taking operational decisions, such as holding, skipping, etc. Presently, it is a regulator, who performs these real time tasks and controls the urban network traffic by treating a real time passenger information system and automatic bus location system. This information includes:

- Departure time of buses from the last passed station;

- Load on buses departing their last passed station;

- $\quad$ Running time for each bus between stations

However, the information will not be known such as:

- Passenger arrival rate;

- Passenger alighting fraction at stations.

\subsection{Data Requirements}

In this paper, it is assumed that the following information is either available or could be estimated:

- Actual departure time of buses from the most recently passed stations;

- Bus running times between stations;

- Passenger arrival rate;

- Passenger alighting fraction

\subsection{Notation}

The following notation is used in the proposed formulations:
$B \quad$ Set of buses in the network

$N \quad$ Set of lines in the network

$S$

$T$

Maximum transfer time

$C_{\max } \quad$ Capacity of bus

$C_{i j}^{l} \quad$ Load of bus $l$ departing the station $i$ of line $j$

$D_{i j}^{l} \quad$ Number of passengers demand for bus $l$ at the station $i$ of line $j$

$t a_{i j}^{l} \quad$ Arrival time of bus $l$ at the station $i$ of line $j$

$t d_{i j}^{l} \quad$ Departure time of bus $l$ at the station $i$ of line $j$

$h_{i j} \quad$ Headway of the line $j$ at the station $i$

$\mu_{i j}^{l}(t) \quad$ Passenger arrival pattern at the station $i$ for bus $l$ of line $j$

$C_{i j k}^{l m} \quad$ Number of passengers transfer pattern from bus $l$ of line $j$ to bus $m$ of line $k$ at station $i$

$n r t_{i j}^{l} \quad$ Number of passengers left behind by bus $l$ at the station $i$ of line $j$

ndes $_{i j}^{l} \quad$ Passenger alighting at the station $i$ for bus $l$ of line $j$

$\varsigma_{i j}^{l} \quad$ Passenger alighting fraction at the station $i$ for bus $l$ of line $j$

$y_{i j k}^{l m} \quad$ Transfer variable which is one if a transfer from bus $l$ of line $j$ to bus $m$ of line $k$ at station $i$ is possible and optimal; zero otherwise.

$\tau_{b} \quad$ Boarding passenger service time (s/p)

$\tau_{a} \quad$ Alighting passenger service time (s/p)

\section{MATHEMATICAL MODEL}

\subsection{Objective Function}

The objective function is sum of the waiting time of non-transferring and transferring passengers at any stations. If bus $l$ is full (overloaded bus $C_{i j}^{l}=C_{\max }$ ) when departing from station $i$, there will be an additional waiting time for passengers who could not board that bus. These passengers are assumed to wait $n r t_{i j}^{l}\left(t d_{i j}^{l+1}-t d_{i j}^{l}\right)$ minutes for the next bus. The total waiting time of non-transferring and transferring passengers is then calculated as: 


$$
\begin{aligned}
& \sum_{i}^{S} \sum_{j}^{N} \sum_{l}^{B}\left(\int_{t d_{i j}^{l-1}}^{t d_{i j}^{l}} \mu^{l}{ }_{i}(t)\left(t d_{i j}^{l}-t d_{i j}^{l-1}-t\right) d t\right. \\
& \left.+n r t_{i, j}^{l-1}\left(t d_{i, j}^{l+1}-t d_{i, j}^{l}\right)\right) \\
& +\sum_{i}^{S} \sum_{j}^{N} \sum_{k \neq j}^{N} \sum_{l}^{B} \sum_{m}^{B} y_{i j k}^{l m} C_{i j k}^{l m}\left(t d_{i k}^{m}-t a_{i j}^{l}\right)
\end{aligned}
$$

The first term in the objective function computes the total waiting time for all passengers who arrive randomly at their stations since the last bus departed that station. The second term computes the total transfer times for all transfers passengers.

\subsection{Capacity Constraint Function}

In fact, the number of passengers who wait at a station can exceed the bus capacity $C_{\max }$. If the number of passengers alighting at station $i$ is:

$$
\operatorname{ndes}_{i j}^{l}=\varsigma_{i j}^{l} C_{i j}^{l}
$$

the number of passenger who cannot board bus $l$ and waiting for bus $l+1$ is calculated:

$$
\begin{aligned}
& n r t_{i j}^{l}=\left(C_{i-1 j}^{l}\left(1-\varsigma_{i j}^{l}\right)+\mu_{i j}^{l}\left(t d_{i j}^{l}-t d_{i j}^{l-1}\right)+n r t_{i j}^{l-1}\right) \\
& -C_{\max }
\end{aligned}
$$

Hence, the capacity of bus $l$ departing station $i$ of line $j$ is calculated: $C_{i j}^{l}=\left[\begin{array}{l}C_{\max } \\ \left(C_{i-1 j}^{l}\left(1-\varsigma_{i j}^{l}\right)+\mu_{i j}^{l}\left(t d_{i j}^{l}-t d_{i j}^{l-1}\right)+n r t_{i j}^{l-1}\right)\end{array}\right.$

\subsection{Formulation}

The objective of this model is to reduce the effect of disturbance on passengers' waiting time and transfer times in bus transit network. The question this paper attempts to answer is which bus has to be held at station or has to be accelerated in order to minimize the total waiting time. Then the mathematical programming problem could be presented as:

Minimize

$$
\begin{aligned}
& \sum_{i}^{S} \sum_{j}^{N} \sum_{l}^{B}\left(\int_{t d_{i j}^{l-1}}^{t} \mu_{i j}^{l}{ }_{i}(t)\left(t d_{i j}^{l}-t d_{i j}^{l-1}-t\right) d t\right. \\
& \left.+n r t_{i, j}^{l-1}\left(t d_{i, j}^{l+1}-t d_{i, j}^{l}\right)\right) \\
& +\sum_{i}^{S} \sum_{j}^{N} \sum_{k \neq j}^{N} \sum_{l}^{B} \sum_{m}^{B} y_{i j k}^{l m} C_{i j k}^{l m}\left(t d_{i k}^{m}-t a_{i j}^{l}\right)
\end{aligned}
$$

Subject to:

$$
\begin{gathered}
C_{i j}^{l} \leq C_{\max }, \forall i, j, l \\
\begin{array}{c}
D_{i j}^{l}=C_{i-1 j}^{l}\left(1-\varsigma_{i j}^{l}\right)+\mu_{i j}^{l}\left(t d_{i j}^{l}-t d_{i j}^{l-1}\right)+n r t_{i j}^{l-1} \\
\forall i, j, l \geq 1
\end{array} \\
n r t_{i j}^{l}=\max \left\{0, D_{i j}^{l}-C_{\max }\right\}, \forall i, j, l
\end{gathered}
$$

$$
\begin{gathered}
t a_{i j}^{l}-t a_{i j}^{l-1} \leq h_{i j}, \forall i, j, l \geq 1 \\
y_{i j k}^{l m}\left(t d_{i k}^{m}-t a_{i j}^{l}\right) \leq T, \forall i, j, k, l, m \\
y_{i j k}^{l m}=\{0,1\}, \forall i, j, k, l, m \\
t d_{i j}^{l}, t a_{i j}^{l}, \varsigma_{i j}^{l}, n r t{ }_{i j}^{l} \geq 0, \forall i, j, l
\end{gathered}
$$

Constraint (6) restricts the number of passengers on board when the bus departs the station. The demand for bus $l$ at station $i$ is calculated by constraint (7) .

Constraint (8) shows that the value $n r t_{i j}^{l}$ depends on the demand for bus $l$ at station $i$, and on the number of available seats on the bus $l$ after alighting. Constraint (9) states that the headway should not be large than a stipulated maximum headway $h_{i j}$. Constraint (10) restricts the transfer time for any transfer. Constraint (11) assures that a transfer from bus $l$ of line $j$ to bus $m$ of line $k$ at station $i$ is possible or not possible.

In the above formulation the variable $y_{i j k}^{l m}$ is binary, taking one or zero, this make the search space discrete. Otherwise the objective function, the constraints (8), (10) makes the formulation (5) becomes nonlinearity.

Thus, the real time of bus routing and scheduling problem is inadequate to solve with classical methods [2], [6]. For this reason, we have studied a genetic approach, developed in section 4 , to solve the problem.

\section{APPROACH GENETIC ALGORITHMS(GA)}

\subsection{Introduction}

A genetic algorithm (GA) is a search technique used in computer science to find approximate solutions to optimization and search problems. Genetic algorithms are typically implemented as a computer simulation in which a population of abstract representations (called chromosomes) of candidate solutions (called individuals) to an optimization problem evolves toward better solutions. Traditionally, solutions are represented in binary as strings of 0 s and 1s, but different encodings are also possible. The evolution starts from population of completely random individuals and happens in generations. In each generation, the fitness of the whole population is evaluated, multiple individuals are stochastically selected from the current population (based on their fitness), modified (mutated or recombined) to form a new population, which becomes current in the next iteration of the algorithm [3] [8]. In the industrial domain, the use of such algorithms has been a subject of a variety of research studies, especially, concerning scheduling of urban transport network [1] [5] [7]. 


\subsection{Coding For The Rescheduling Problem}

The solution coding for the rescheduling problem of [2], [6] is illustrated in Fig. 1

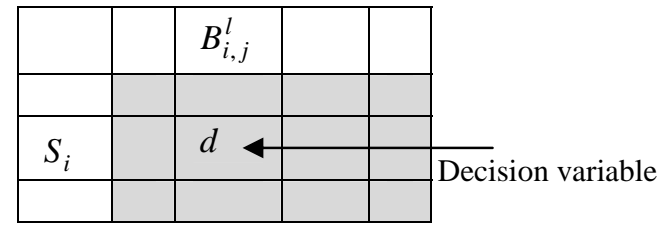

Figure. 1. Solution coding

Each cell illustrates the decision to undertake for the buses of $B$ at the different stations of $S$. The decision $d$ is defined, the differences between the rescheduled and the expected departure time.

The decisions for each $B_{j}^{l}$ are:

- Accelerate if $d<0$;

- Holding at stations if $d>0$;

- Do nothing if $d=0$.

Moreover, the decisions will be applied to the initial theoretical timetable of buses. In case of acceleration, the constraint of course duration between two stations is violated with this type of coding. So for the respect of all the constraints of the problem, [4] defines a new coding, that contains the departure time of the buses at the different stations. The final departure time obtained will not be any more of the decisions that it is then necessary to apply for the initial theoretical timetable of buses, as it was the case in [2], but it will be the same as the solution timetables of buses.

In [2], [4], the authors utilized the departure time as the decision variable, and considered the theoretical timetable as the departure time of buses at stations. In reality, the theoretical timetable is arrival times of buses at stations. These types of coding have the inconvenience of a reduced exploitation of the search space.

In this paper, we present a new coding, which enhances the exploration of the search space. The solution of this rescheduling problem deals with finding the new schedules that satisfy different constraint.

The rescheduling problem has three decision variables such as arrival time, departure time and transfer variable.

We present each variable at each station for each line with substring. In this coding, arrival time, and departure time are recalculated (13), (14), based on the duration, between bus $l$ and $l-1$, the duration for passengers boarding and alighting, with an initial condition $t d_{i j}^{0}=0$

$$
\begin{aligned}
& t a_{i j}^{l}=t d_{i j}^{l-1}+h_{i j} \\
& t d_{i j}^{l}=t a_{i j}^{l}+\tau_{a} n d e s_{i j}^{l}+\tau_{b}\left(\mu_{i j}^{l} h_{i j}-n r t_{i j}^{l}\right)
\end{aligned}
$$

Finally, we concatenate all variables for other lines together to get complete string. Tables 1(a) and 1(b) describe elements of the encoding and an encoding example.
Table 1 (a) Chromosome encoding; (b) Chromosome encoding example.

\begin{tabular}{|c|}
\hline$t a_{11}^{1}$ \\
\hline$t a_{11}^{2}$ \\
\hline$t a_{11}^{3}$ \\
\hline$\cdots \cdot$ \\
\hline$\cdots \cdot$ \\
\hline$t a_{S-1 N-1}^{B-1}$ \\
\hline$t a_{S N}^{B}$ \\
\hline
\end{tabular}

(a)

\begin{tabular}{|c|}
\hline 9h:10 \\
\hline 9h:23 \\
\hline 9h:25 \\
\hline $11 \mathrm{~h}: 00$ \\
\hline $11 \mathrm{~h}: 17$ \\
\hline $10 \mathrm{~h} 45$ \\
\hline $11 \mathrm{~h}$ \\
\hline
\end{tabular}

(b)

\subsection{Crossover Operator}

Crossover is a genetic operator used to vary the programming of a chromosome or chromosomes from one generation to the next. To explore our search space, crossover biases is used (based on arrival times and boarding time for each passenger). We present in Figure 2 , an example of the crossover biases.

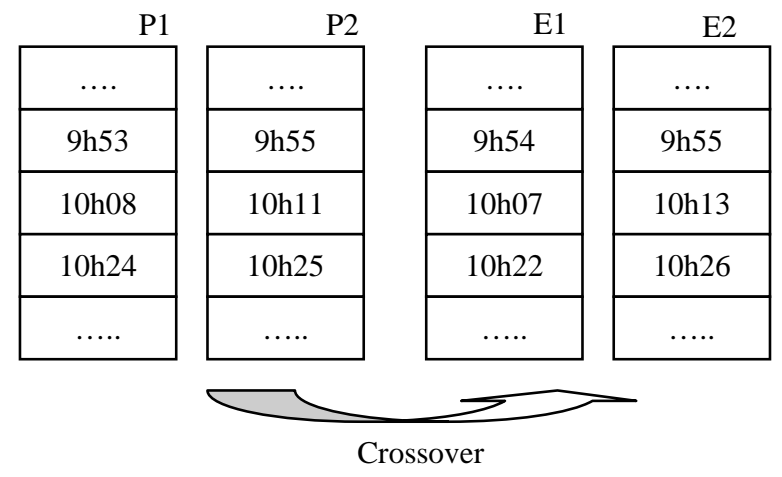

Figure 2. Crossover example.

\subsection{Mutation}

Mutation is a genetic operator used to maintain genetic diversity from one generation of a population of chromosomes to the next. It will be carried out depending on the mutation probability $p_{m}$. In this paper we use $p_{m}=0.005$. The algorithm was coded in Visual C 6.0 and implemented on a Pentium $\mathrm{M}$ with $1.7 \mathrm{GHz}$ CPU.

\section{SIMULATION RESULTS}

\subsection{Illustrative Example}

Consider a branch of bus network at Grenoble in France, composed of $N=3$ lines (Fig. 3). These three lines (line 11, line 12, and line 13) are crossed in station $S_{2,3}$. Each line contains 5 stations and reserved by 3 buses. A disturbance affects the second bus $B_{11}^{2}$ of line 11. This disturbance is detected at 9h05 and bus 
$B_{11}^{2}$ arrived at station $S_{2} 12$ minutes late. So, the transit operation with $B_{13}^{2}$ and $B_{12}^{2}$ would not occur at station $S_{2,3}$. Theoretical timetable of three lines are given in Table 2. The disturbed timetable is shown in Table 3.

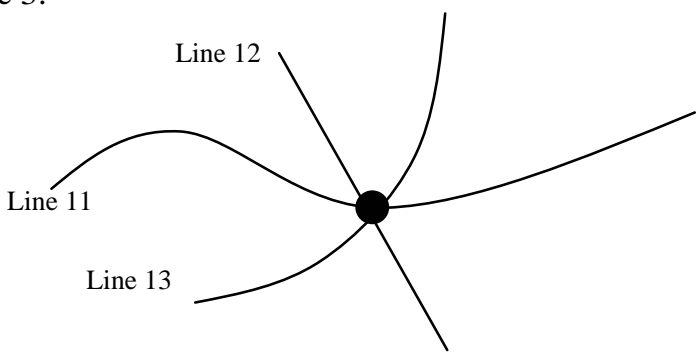

Figure. 3. Structure of network studied
The parameters for rescheduling problem:

- Passenger arrivals at each station is a stationary Poisson process;

- Passenger alighting fraction at each station is given, boarding passenger service time $\tau_{b}=2.4 \mathrm{~s}$ (0.04 minute), passenger transfer pattern $=50 \%$ of passengers, who alighting at transfer station, bus capacity $C_{\text {max }}=55$, maximum transfer time at each station $T=10$ minutes.

The following GA parameters are used:

- Population size is 200, number of generations are 100, crossover probability is $p_{c}=0.95$ mutation with probability $p_{m}=0.005$

The all parameters for the rescheduling problem of the line 11, line 12, and line 13 are summarized in Table 4,5 .

Table 2. Theoretical timetables of the three lines 11,12 , and 13.

\begin{tabular}{|l|l|l|l|l|l|l|l|l|l|l|l|}
\hline & $B_{11}^{1}$ & $B_{11}^{2}$ & $B_{11}^{3}$ & & $B_{12}^{1}$ & $B_{12}^{2}$ & $B_{12}^{3}$ & & $B_{13}^{1}$ & $B_{13}^{2}$ & $B_{13}^{3}$ \\
\hline$S_{1,11}$ & $8 \mathrm{~h} 24$ & $8 \mathrm{~h} 49$ & $9 \mathrm{~h} 14$ & $S_{1,12}$ & $8 \mathrm{~h} 33$ & $9 \mathrm{~h} 03$ & $9 \mathrm{~h} 27$ & $S_{1,13}$ & $8 \mathrm{~h} 33$ & $9 \mathrm{~h} 03$ & $9 \mathrm{~h} 22$ \\
\hline$S_{2,11}$ & $8 \mathrm{~h} 35$ & $9 \mathrm{~h} 00$ & $9 \mathrm{~h} 25$ & $S_{2,12}$ & $8 \mathrm{~h} 41$ & $9 \mathrm{~h} 11$ & $9 \mathrm{~h} 35$ & $S_{2,3}$ & $8 \mathrm{~h} 43$ & $9 \mathrm{~h} 13$ & $9 \mathrm{~h} 32$ \\
\hline$S_{2,3}$ & $8 \mathrm{~h} 40$ & $9 \mathrm{~h} 05$ & $9 \mathrm{~h} 30$ & $S_{2,3}$ & $8 \mathrm{~h} 44$ & $9 \mathrm{~h} 14$ & $9 \mathrm{~h} 38$ & $S_{3,13}$ & $8 \mathrm{~h} 50$ & $9 \mathrm{~h} 20$ & $9 \mathrm{~h} 39$ \\
\hline$S_{4,11}$ & $8 \mathrm{~h} 42$ & $9 \mathrm{~h} 07$ & $9 \mathrm{~h} 32$ & $S_{4,12}$ & $8 \mathrm{~h} 46$ & $9 \mathrm{~h} 16$ & $9 \mathrm{~h} 41$ & $S_{4,13}$ & $9 \mathrm{~h} 02$ & $9 \mathrm{~h} 32$ & $9 \mathrm{~h} 51$ \\
\hline$S_{5,11}$ & $8 \mathrm{~h} 47$ & $9 \mathrm{~h} 12$ & $9 \mathrm{~h} 37$ & $S_{5,12}$ & $8 \mathrm{~h} 48$ & $9 \mathrm{~h} 18$ & $9 \mathrm{~h} 43$ & $S_{5,13}$ & $9 \mathrm{~h} 14$ & $9 \mathrm{~h} 43$ & $10 \mathrm{~h} 02$ \\
\hline
\end{tabular}

Table 4 Parameters of two lines 12, 13

\begin{tabular}{|c|c|c|c|c|c|c|c|c|}
\hline Station & \multicolumn{2}{|c|}{$\begin{array}{l}\text { Frequency } \\
\text { Line } 12\end{array}$} & \multirow{2}{*}{$\begin{array}{r}\begin{array}{c}\text { Passenger } \\
\text { arrival } \\
\text { rate }\end{array} \\
0,6\end{array}$} & \multirow{2}{*}{$\begin{array}{r}\begin{array}{c}\text { Passenger } \\
\text { alighting } \\
\text { fraction }\end{array} \\
0,4\end{array}$} & \multicolumn{2}{|c|}{$\begin{array}{c}\text { Frequency } \\
\text { Line } 13\end{array}$} & \multirow{2}{*}{$\begin{array}{r}\begin{array}{c}\text { Passenger } \\
\text { arrival } \\
\text { rate }\end{array} \\
0,6\end{array}$} & \multirow{2}{*}{$\begin{array}{r}\begin{array}{c}\text { Passenger } \\
\text { alighting } \\
\text { fraction }\end{array} \\
0,4\end{array}$} \\
\hline 1 & 30 & 24 & & & 30 & 19 & & \\
\hline 2 & 30 & 24 & 0,5 & 0,6 & 30 & 19 & 1 & 0,8 \\
\hline 3 & 30 & 24 & 1 & 1 & 30 & 19 & 1,2 & 0,8 \\
\hline 4 & 30 & 24 & 1 & 0,5 & 30 & 19 & 1 & 0,5 \\
\hline 5 & 30 & 24 & 0,2 & 1 & 30 & 19 & 1 & 1 \\
\hline
\end{tabular}

Table 3. Disturbed timetables of the line 11

\begin{tabular}{|l|c|l|l|}
\hline & $B_{11}^{1}$ & $B_{11}^{2}$ & $B_{11}^{3}$ \\
\hline$S_{1,11}$ & $8 \mathrm{~h} 24$ & $8 \mathrm{~h} 49$ & $9 \mathrm{~h} 14$ \\
\hline$S_{2,11}$ & $8 \mathrm{~h} 35$ & $9 \mathrm{~h} 00$ & $9 \mathrm{~h} 25$ \\
\hline$S_{2,3}$ & $8 \mathrm{~h} 40$ & $9 \mathrm{~h} 17$ & $9 \mathrm{~h} 30$ \\
\hline$S_{4,11}$ & $8 \mathrm{~h} 42$ & $9 \mathrm{~h} 19$ & $9 \mathrm{~h} 32$ \\
\hline$S_{5,11}$ & $8 \mathrm{~h} 47$ & $9 \mathrm{~h} 24$ & 9h37 \\
\hline
\end{tabular}

Table 5. Parameters of line 11

\begin{tabular}{|r|r|r|r|}
\hline Station & Frequency & $\begin{array}{c}\text { Passenger } \\
\text { arrival rate }\end{array}$ & $\begin{array}{c}\text { Passenger } \\
\text { alighting fraction }\end{array}$ \\
\hline 1 & 25 & 0,6 & 0,4 \\
\hline 2 & 25 & 1,5 & 0,6 \\
\hline 3 & 25 & 1,5 & 0,7 \\
\hline 4 & 25 & 0,7 & 0,5 \\
\hline 5 & 25 & 0,2 & 1 \\
\hline
\end{tabular}

\subsection{Results}

The solution given by our GA is illustrated in Table 6 , and the detail of objective function value is illustrated in Table 7. In this solution, decision which will be applied to buses $B_{11}^{2}, B_{12}^{2}$, and $B_{13}^{2}$ are both delay (holding) and accelerating. For transferring, bus $B_{12}^{2}$ is held 4 minutes, and $B_{13}^{2}$ is held 5 minutes at station $S_{2,3}$.

The total waiting time for all passengers nontransferring and transferring at any stations has a value of 10212 minutes in case of disturbances. If the regulator does nothing, the expected total waiting time for all passengers will increase by 1570 minutes (10212-8642=1570). The solution found after $15 \mathrm{~s}$ computational time is to hold bus $B_{12}^{2} 4$ minutes, 
and $B_{13}^{2} 5$ minutes at station $S_{2,3}$. The total waiting time for all passengers non-transferring and transferring at any stations has a value of 10003 minutes. Otherwise, the total time waiting time for passenger non-transferring has been increased by 3.6\% ((9439-9783)/9439), and the total waiting time for transferring passengers has been reduced by $71.5 \%$ $((773-220) / 773))$.

\section{CONCLUSION}

This paper presented a modified mathematical model for rescheduling applicable to urban bus transit operation. The developed model is flexible in adapting to buses capacities conditions when a given bus departs a station along a given line when the disturbances happen. A heuristic algorithms based on GA is presented for solving the model. The efficiency of the algorithms was tested using numerical examples. The results indicate that applying both delay (holding) and accelerating can reduce largely the waiting time for transferring passengers in local, and the total waiting time for the all passengers in global. The respective of this research work need in the comparison with other methods, develop other control strategies (Stopskipping, adding a reserve bus...), the presentation of other mode of transport (Tramway, Metro...).

Table 6. Solution timetables of three lines

\begin{tabular}{|l|l|l|l|l|l|l|l|l|l|l|l|}
\hline & $B_{11}^{1}$ & $B_{11}^{2}$ & $B_{11}^{3}$ & & $B_{12}^{1}$ & $B_{12}^{2}$ & $B_{12}^{3}$ & & $B_{13}^{1}$ & $B_{13}^{2}$ & $B_{13}^{3}$ \\
\hline$S_{1,11}$ & $8 \mathrm{~h} 24$ & $8 \mathrm{~h} 49$ & $9 \mathrm{~h} 14$ & $S_{1,12}$ & $8 \mathrm{~h} 33$ & $9 \mathrm{~h} 03$ & $9 \mathrm{~h} 27$ & $S_{1,13}$ & $8 \mathrm{~h} 33$ & $9 \mathrm{~h} 03$ & $9 \mathrm{~h} 22$ \\
\hline$S_{2,11}$ & $8 \mathrm{~h} 35$ & $9 \mathrm{~h} 00$ & $9 \mathrm{~h} 25$ & $S_{2,12}$ & $8 \mathrm{~h} 41$ & $9 \mathrm{~h} 11$ & $9 \mathrm{~h} 35$ & $S_{2,3}$ & $8 \mathrm{~h} 43$ & $9 \mathrm{~h} 18$ & $9 \mathrm{~h} 32$ \\
\hline$S_{2,3}$ & $8 \mathrm{~h} 40$ & $9 \mathrm{~h} 17$ & $9 \mathrm{~h} 30$ & $S_{2,3}$ & $8 \mathrm{~h} 44$ & $9 \mathrm{~h} 18$ & $9 \mathrm{~h} 38$ & $S_{3,13}$ & $8 \mathrm{~h} 50$ & $9 \mathrm{~h} 25$ & $9 \mathrm{~h} 39$ \\
\hline$S_{4,11}$ & $8 \mathrm{~h} 42$ & $9 \mathrm{~h} 19$ & $9 \mathrm{~h} 32$ & $S_{4,12}$ & $8 \mathrm{~h} 46$ & $9 \mathrm{~h} 20$ & $9 \mathrm{~h} 41$ & $S_{4,13}$ & $9 \mathrm{~h} 02$ & $9 \mathrm{~h} 36$ & $9 \mathrm{~h} 51$ \\
\hline$S_{5,11}$ & $8 \mathrm{~h} 47$ & $9 \mathrm{~h} 23$ & $9 \mathrm{~h} 37$ & $S_{5,12}$ & $8 \mathrm{~h} 48$ & $9 \mathrm{~h} 21$ & $9 \mathrm{~h} 43$ & $S_{5,13}$ & $9 \mathrm{~h} 14$ & $9 \mathrm{~h} 47$ & $10 \mathrm{~h} 02$ \\
\hline
\end{tabular}

Table 7. Computation results for the example

\begin{tabular}{|c|c|c|}
\hline & Waiting time & Transfer time \\
\hline Theoretical & $(1)$ & $(2)$ \\
\hline Line 11 & 2813 & 323 \\
\hline Line 12 & 2435 & 0 \\
\hline Line 13 & 3026 & 46 \\
\hline Total & 8274 & 368 \\
\hline$(1)+(2)$ & & 8642 \\
\hline Disturbed & (1) & (2) \\
\hline Line 11 & 3978 & 603 \\
\hline Line 12 & 2435 & 0 \\
\hline Line 13 & 3026 & 170 \\
\hline Total & 9439 & 773 \\
\hline$(1)+(2)$ & & 10212 \\
\hline Rescheduled & (1) & (2) \\
\hline Line 11 & 3973 & 140 \\
\hline Line 12 & 2506 & 0 \\
\hline Line 13 & 3304 & 80 \\
\hline Total & 9783 & 220 \\
\hline$(1)+(2)$ & & 10003 \\
\hline
\end{tabular}

\section{REFERENCES}

[1] Anthony Wren, David O,"A genetic algorithms for public transport driver scheduling", Computers and Operations Research, Vol. 22, No. 1, pp101-110, 1995. [2] Besma Fayech, " Régulation des réseaux de transport multimodal : Systèmes multi agents et algorithmes évolutionnistes”, Thèse de doctorat, Université des Sciences et Technologies de Lille, 2003.
[3] D.E. Goldberg, "Genetic algorithms in search optimization, and machine learning”, Addison-Wesley, 412p, 1989.

[4] Mahjoub DRIDI, "Contribution à la résolution des problèmes de régulation dans les systèmes de transport dans un contexte multicritères par approche évolutionniste", Thèse de doctorat. Université des Sciences et Technologies de Lille, 2004.

[5] M.T. Isaai and N.P. Cassaigne, "Predictive and Reactive Approaches to the Train Scheduling Problem: A Knowledge Management Perspective", IEEE Transactions on Systems, Man, and Cybernetics Part C: Applications and Reviews, Vol. 31, No. 4, pp. 476-484, 2001.

[6] Pierre Borne, Besma Fayech, Slim Hammadi, Salah Maouche,”Decision support system for urban transportation networks", IEEE Transactions on Systems, Man and Cybernetics, Part C, Vol. 33, No. 1, pp67-77, 2003.

[7] V. Tom, S. Mohan, ” Transit route network design using frequency coded genetic algorithms", Journal of transportation engineering, Vol. 129, No. 2, pp186195, 2003.

[8] Randy L. Haupt, Sue Elle. Haupt, "Practical Genetic Algorithms", New York Chichester John Wiley, 272p, 1998. 